\title{
PALYNOLOGY OF A PEAT IN PARQUE NACIONAL DE APARADOS DA SERRA, RIO GRANDE DO SUL, BRAZIL
}

\section{INTRODUCTION}

The purpose of this paper was to obtain some data about paleoenvironments and paleoclimates of the last millenia in the region of Parque Nacional de Aparados da Serra, Rio Grande do Sul, Brazil.

This park is situated at a height of about $1,000 \mathrm{~m}$, lat. $29^{\circ} 15^{\prime}-29^{\circ} 25^{\prime} \mathrm{S}$ and long. $50^{\circ} 00^{\prime}-$ $50^{\circ} 15^{\prime} \mathrm{W}$. Its vegetation today is subtropical, where fields predominate and on which, like a mosaic, grow Araucaria forests. At the lower parts of the fields there are peats. The region consists of basaltic rocks.

\section{MATERIAL AND METHODS}

The profile of the sediments of a peat were collected using a Hiller sampler several times. This profile consisted of $343 \mathrm{~cm}$ of peat and $126 \mathrm{~cm}$ of the gray clay layer directly under it.

Thirty seven samples of $\mathbf{2} \mathrm{g}$ each were taken from this profile at regular intervals. The chemical processing was according to the traditional method, after FAEGRI \& IVERSEN (1975), and slides were made after SALGADO-LABOURIAU (1973).

The quantitative pollen analysis is expressed in percentage (Fig. 1), and in absolute values (Fig. 2), with the use of Lycopodium clavatum tablets, after STOCKMARR (1971). The counting was of $\mathbf{5 0 0}$ grains in each sample, leaving out all typic pollen matter of today's vegetation on this peat and this was counted separately. Thus, the percentage of each one of the autochtonous elements were calculated

\footnotetext{
$\overline{1}$ Universidade Federal do Rio Grande do Sul, 91500 - Porto Alegre, Brazil.
} 


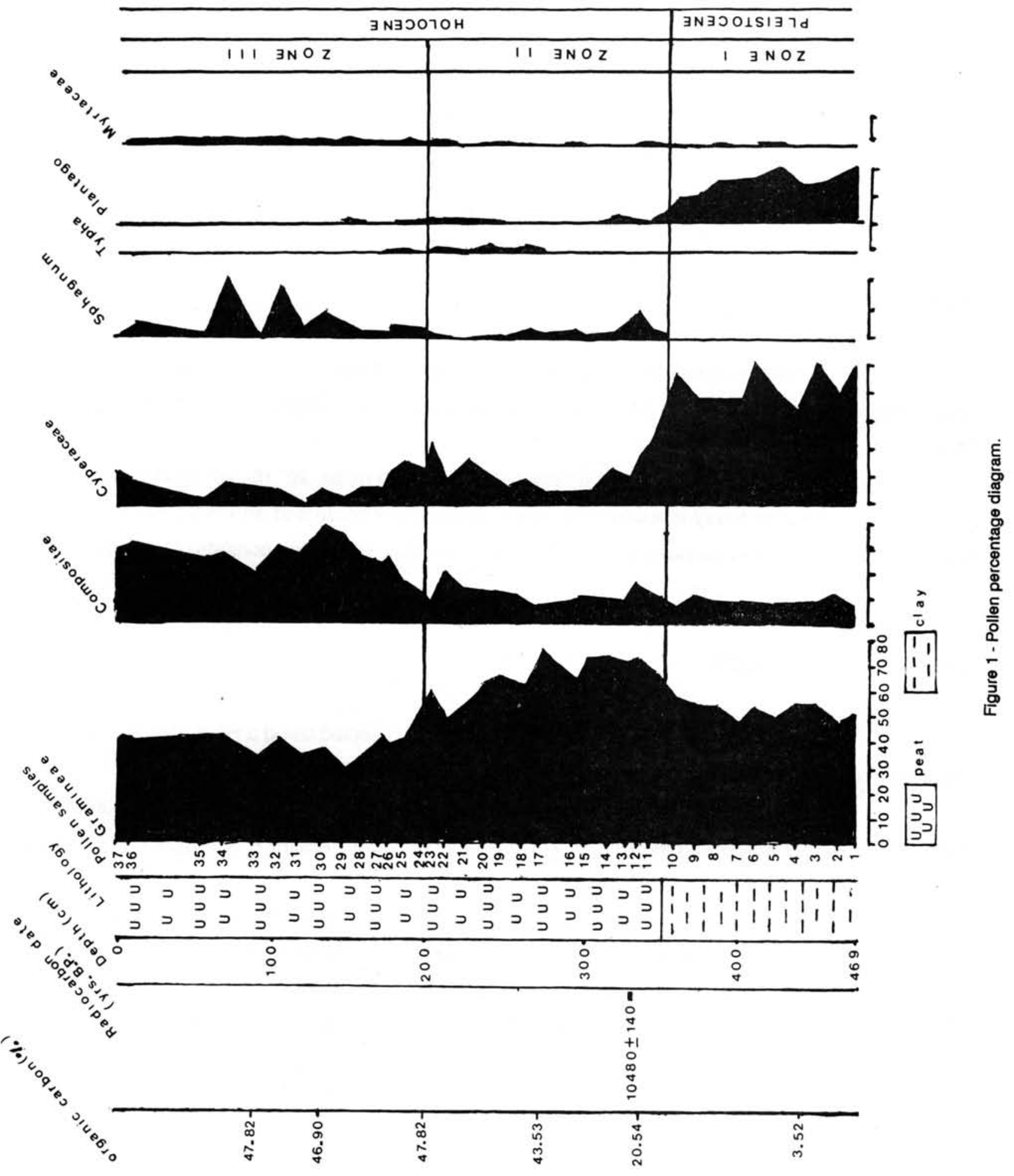




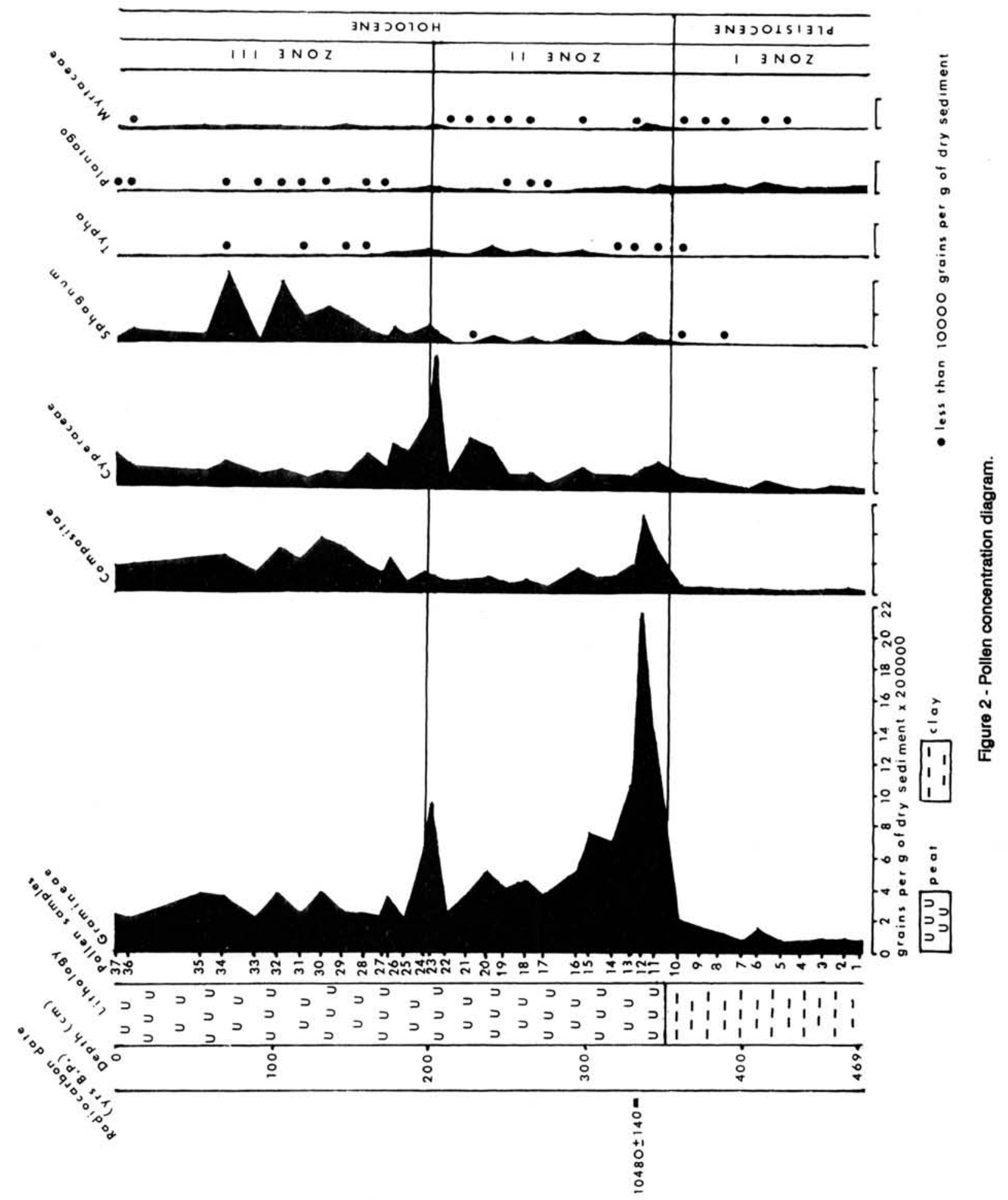


over their own total. The same was done for the allochthonous elements.

Here there appear briefly only some of the most important pollen elements.

The radiocarbon date was calculated at Beta Analytic Inc. Laboratory, Florida, USA.

The organic carbon content was analysed at Departamento de Solos of Faculdade de Agronomia, Universidade Federal do Rio Grande do Sul, Brazil.

\section{RESULT OF ANALYSIS}

The results obtained show three distinct zones in the pollen diagram (Figs. 1-2).

The dating in 10,480 years B.P. for the beginning of the peat formation points zone $I$ as corresponding to the end of the Pleistocene. The gray clay sediments, poor in organic carbon (Fig. 1) correspond to zone I, possibly from an incipient water reservoir in the depression of the basaltic rocks. The scarce pollen concentration of this zone (Fig. 2) must correspond to a semi-arid climate, where the main elements of vegetation were only Gramineae and a few Compositae. The significative representativeness of Plantago in zone I seems to be related to environmental conditions still influenced by the low temperatures of the end of the Pleistocene. The Cyperaceae of this phase must probably correspond to the aquatic vegetation of the banks of this water reservoir. The semi-arid climate might have caused the rapid rock erosion, thus increasing the sedimentation rate in the lower parts. This may also have contributed to the scarcity of pollen and spores in zone I sediments.

About 11,000 years B.P. an abrupt climate change seems to have taken place, with possibly rising temperatures and a higher rainfall rate, marking the beginning of the Holocene (zone II).

Zone II corresponds to peat sediments, consisting of dark mud, rich in organic carbon (Fig. 1), in clear contact with the gray sediments of the former zone. The beginning of peat accumulation at the site is an indication of a hydrological change, so that more water was retained in the primitive water reservoir.

The improvement of climatic conditions influenced the vegetation as a whole, as is apparent in the abrupt changes of the pollen diagrams (Figs. 1-2). Gramineae here reach the highest percentages of the whole profile (Fig. 1) and, for the first time, forest elements appear to a greater extent in this region, like Myrtaceae. The development of aquatic vegetation must have caused the rapid filling up of the swamp, favouring the peat formation, with Cyperaceae associated to Typha and the beginning of Sphagnum development. All these elements either appear for the first time in zone II or here have their concentrations strikingly increased in relation to zone I. The percentages of Gramineae decreased significantly from the beginning to the end of zone II.

Zone III also appears as dark mud sediments, rich in organic carbon (Fig. 1), with a high 
percentage of Sphagnum, that shows the clear development of this peat. The percentages of Cyperaceae, Gramineae and Typha decrease in relation to zone II, while the Compositae percentages increase. Although the Myrtaceae are fow in zone III, they are, nevertheless, more numerous here, showing the development of forests in the region near the peat.

Evidence of human activity appears in the uppermost part of zone III with an abrupt decrease of Sphagnum. These changes must be related especially to drainage in this peat, which gradually has been desiccated. Nowadays this gradual drying process gives place to the surrounding field species and disturbs the development of the peat.

\section{REFERENCES}

FAEGRI, K. \& IVERSEN, J. (1975) Textbook of pollen analysis. 3.ed. New York, Hafner Press. 295p.

SALGADO-LABOURIAU, M.L (1973) Contribuição à palinologia dos Cerrados. Rio de Janeiro, Academia Brasileira de Ciências, 291p.

STOCKMARR, J. (1971) Tablets with spores used in absolute pollen analysis. Pollen et Spores, 13(4):615621. 